\title{
An In vitro Cell-Based LDL Uptake Model for Screening PCSK9 Modulators
}

\author{
Weiming $\mathrm{Xu}^{1,2 *}$ and Lizhi Liu ${ }^{1,2}$ \\ ${ }^{1}$ Department of Molecular Biology and Biotechnology, University of Sheffield, S10 2TN, UK \\ ${ }^{2}$ London Biotech Ltd, 19 Crawley Road, London, N22 6AN, UK
}

\begin{abstract}
PCSK9 plays a critical role in cholesterol metabolism by controlling the level of low-density lipoprotein receptor(LDLR). Recent population genetic studies have shown that PCSK9 is a genetic validated target for the reduction of LDLC. Several anti-PCSK9 antibodies are currently undergoing Phase II/III trails in patients with hypercholesterolemia with promising results. However, developing novel compounds that inhibit PCSK9 function is pharmaceutically preferred over both antibody and siRNA routes. We have recently developed a cell-based, functional assay incorporating recombinant PCSK9 protein for high-throughput screening of human liver cell HepG2. A pilot screen of the NINDS compound library has been successful in identifyng several potential compounds in duplicate screening. One of the lead compounds, colchicine, has been further validated with the Western blot assay for PCSK9-mediated LDLR degradation in dose-reponsive assay. Colchicine is a prescribing drug for the treatment of acute gout flares and familial Mediterranean fever. Identification of colchicine as a modulator of PCSK9 function highlights the potential of the novel use of this drug for cardiovascular disease treatment.
\end{abstract}

Keywords: PCSK9; LDL; High-throughput screen assay; Colchicine; Cholesterol; Modulator; Cardiovascular disease

\begin{abstract}
Abbreviations: PCSK9: Proprotein convertase subtilisin/kexin type 9; NINDS: The National Institute of Neurological Disorders and Stroke compound library; HTS: High-Throughput Assay; CVD: Cardiovascular Disease
\end{abstract}

\section{Introduction}

Cardiovascular Disease (CVD) is among the main causes of premature death in the world. Plasma LDL cholesterol is a major determinant of CVD. Recent genetic studies have shown, one of the key genes, PCSK9, plays a critical role in cholesterol metabolism by controlling the level of low-density lipoprotein receptor(LDLR) [13]. Recent population genetic studies have shown that the nonsense mutations of PCSK9 were associated with a 28 percent reduction in mean LDLc, and an 88 percent reduction in the risk of a CVD in African-American, indicating PCSK9 is a genetic validated target for the reduction of LDLc in human population [4].

PCSK9 inhibition is currently a "hot drug target" for developing new cholesterol lowering therapy. Therapeutic RNAi targeting PCSK9 gene has been shown to have profound LDLc lowering effect in rodents and nonhuman primates [5]. Several pharmarceutical companies have developed therapeutic antibodies against PCSK9 for treatment of CVD. At least five phase II clinicla trails of patients with AMG 145 antibodies(Amgen) or SAR236553/REGE727 antibody(Regeneron Pharmarceutical) indicated that anti-PCSK9 antibodies reduced LDL in patients with hypercholesterolemia [6].

However, developing novel compounds that inhibit PCSK9 function is pharmaceutically preferred over both antibody and siRNA routes. We have recently developed a cell-based, functional assay incorporating recombinant PCSK9 protein for high-throughput screening of human liver cell HepG2. A pilot screen of the NINDS compound library has been carried out and we hve identified several potential compounds in duplicate screening and one of the compounds, colchicine, has been validated with a western blot assay for PCSK9-mediated LDLR degradation in dose-reponsive assay. This is the first successful assay of its kind developed for screening for PCSK9 inhibitor.

\section{Materials and Methods}

\section{Cell culture, protein purification and western blot assays}

HepG2 cells were obtained from European collection of cell culture (Wiltshire, UK). Cells were grown in the DMEM medium containing $25 \mathrm{mM}$ glucose and $10 \%$ foetal calf serum, as described [7]. A stable expressed FLAG-tagged wild-type PCSK9 cell line and a 'gain-offunction' mutant PCSK9-D374Y cell line were developed as previously describe [8]. The FLAG-tagged PCSK9 protein was isolated using the FLAG-immunoprecipitation kit (Sigma) following by elution with the 3xFLAG peptide (final concentration $150 \mathrm{ng} / \mathrm{ml}$ of 3xFLAG peptide) [8]. The protein purity was determined by SDS-PAGE and visualized by Coomassie Blue stain with over $90 \%$ purity. Protein concentration was measured using Bio-Rad Protein Assay kit (Cat: 500-0006, BioRad. UK). The anti-human LDLR antibody was a rabbit antibody directed against amino acids 184-196 of human LDLR (Research Diagnostics Inc. Flanders, NJ, USA). Anti-human PCSK9 antibody was from the Cayman Chemical(Cat: 10007185, Cayman, USA). Cell lysis and western blot analysis were carried out as preciously described [7]. Western blot densitometry was carried out using the Vision works LS software (UVP, Cambridge, UK). All data were analysed by GB-Stat V5.4.4 program using student $\mathrm{t}$-Test (two-tailed). The cell viability was determined by the trypan blue staining using the Trypan blue exclusion solution( Gibco, Cat 15250-061, Life Technologies Ltd, Paisley, UK).

${ }^{*}$ Corresponding author: Weiming $\mathrm{Xu}$, Department of Molecular Biology and Biotechnology, University of Sheffield, S10 2TN, UK, Tel: 01142222 785; E-mail: Weiming.xu@sheffield.ac.uk

Received October 25, 2013; Accepted November 27, 2013; Published December 04, 2013

Citation: Xu W, Liu L (2013) An In vitro Cell-Based LDL Uptake Model for Screening PCSK9 Modulators. J Bioequiv Availab 5: 248-252. doi:10.4172/jbb.1000168

Copyright: (c) $2013 \mathrm{Xu} \mathrm{W}$, et al. This is an open-access article distributed under the terms of the Creative Commons Attribution License, which permits unrestricted use, distribution, and reproduction in any medium, provided the original author and source are credited. 


\section{NINDS library}

The National Institute of Neurological Disorders and Stroke (NINDS) compound library is a collection of known drugs and pharmacologically active compounds originally collated by the National Institute of Neurological Disorders and Stroke (US) $[9,10]$. The library contains 1041 compounds (http://iccb.med.harvard.edu/ screening/compound_libraries/ninds.htm), a collection of known drugs and pharmacologically active compounds, consisting mainly of FDA-approved drugs, The NINDS library was kindly supplied to us by Dr Nicole Mathon and Dr Catherine Kettleborough from the Medical Research Council Technology, UK(MRCT). All the compounds in the NINDS were dissolved in DMSO at $1 \mathrm{mM}$ concentration, therefore, the sensitivity of the cell-based assay were determined in different dilutions of DMSO on the standard cell culture condition.

High-throughput screening of the cell- based LDL uptake assay

High-throughput screening was carried out in high throughput robotics facility in the university of Sheffield [11]. Human liver HepG2 cells were seeded in 96 well tissue plates at concentration $2 \times 10^{5} \mathrm{cells} / \mathrm{ml}$. After $24 \mathrm{~h}$, the medium was replaced with DMEM medium without FBS and purified PCSK9-D374Y $(1 \mu \mathrm{g} / \mathrm{ml}$ PCSK9=13.4 nM) plus pooling 5 compounds were added, resulting each compound concentration at $200 \mathrm{nM}$. In the positive control wells, only PCSK9-D374Y protein was added. The negative control was vehicle (DMSO) plus medium only. Vehicle (0.2\% DMSO) was used in all assays. After $16 \mathrm{~h}$ incubation, the medium was replaced with fresh medium containing $10 \mu \mathrm{g} / \mathrm{ml}$ Bodipy FL LDL (Cat: L-3483, Invitrogen, UK) without FBS. The cells were incubated for $4 \mathrm{~h}$ at $37^{\circ} \mathrm{C}$. The cells were washed with PBS and LDL uptake was quantified on the Fusion fluorescence plate reader (Packard BioScience, Beaconsfield, UK) with the excitation filter $485 \mathrm{~nm}$ and emission filter $530 \mathrm{~nm}$.

\section{Statistical analysis}

The high-throughput analysis was calculated as Z' factor. The $\mathrm{Z}$ factor was determined according to Zhang et al. [12] using the following equation:

$$
\mathrm{Z}^{\prime}=1-3\left(\mathrm{SD}_{\text {neg }}+\mathrm{SD}_{\text {pos }}\right) / \mid\left(\text { Mean }_{\text {neg }}-\text { Mean }_{\text {pos }}\right) \mid \text {. }
$$

Z' values $>0.5$ have acceptable characteristics for high-throughput screening (HTS).

\section{Secondary screening analysis of PCSK9-mediated LDLR degradation by western blot}

HepG2 cells were seeded in 6 well tissue plates at a concentration of $2 \times 10^{5}$ cells $/ \mathrm{ml}$. After $24 \mathrm{~h}$, the medium was replaced with DMEM medium without FBS and added the purified D374Y-PCSK9 protein $(1 \mu \mathrm{g} / \mathrm{ml})$. In the control experiments, without PCSK9 protein was added. In compound function assay, the test compounds were added together with the purified D374Y-PCSK9 protein. After 16h, cells were washed twice in PBS and harvested for western blot analysis as previous described [8].

\section{Results and Discussion}

\section{Establishment of a cell-based assay}

We have set up a cell-based screening method using fluorescentlabeled LDL uptake in HepG2 cells as an end point assay. We treated human liver HepG2 cells with a 'gain-of-function' mutant D374Y-
PCSK9 protein at $1 \mu \mathrm{g} / \mathrm{ml}$ concentration (13.4 $\mathrm{nM}$ ). As shown in Figure $1 \mathrm{~A}$, the fluorescence -labelled LDL uptake was significantly decreased in the PCSK9-D374Y-treated cells than that of untreated cells. This fluorescence intensity difference can be easily detected by the fluorescence plate reader (Figue 1B, $1^{\text {st }}$ two columns). Because all compounds in our screening assay were dissolved in DMSO, we have further tested the DMSO effects on the PCSK9-mediated LDL uptake. We found that 200 -fold dilution of $\operatorname{DMSO}(0.5 \mu \mathrm{l}$ DMSO into $100 \mu \mathrm{l}$ medium) (Figure $1 \mathrm{~B}, 2^{\text {nd }}$ two columns) worked well in our cell-base assay $(\mathrm{P}<0.05)$ (Figure 1B). Therefore, we have carried out the screening program at this dilution. The $Z$ ' factor of the assay was determined to be 0.52 , indicating this fluorescence-cell based assay would perform well in the large-scale screening process (Figure 1C).

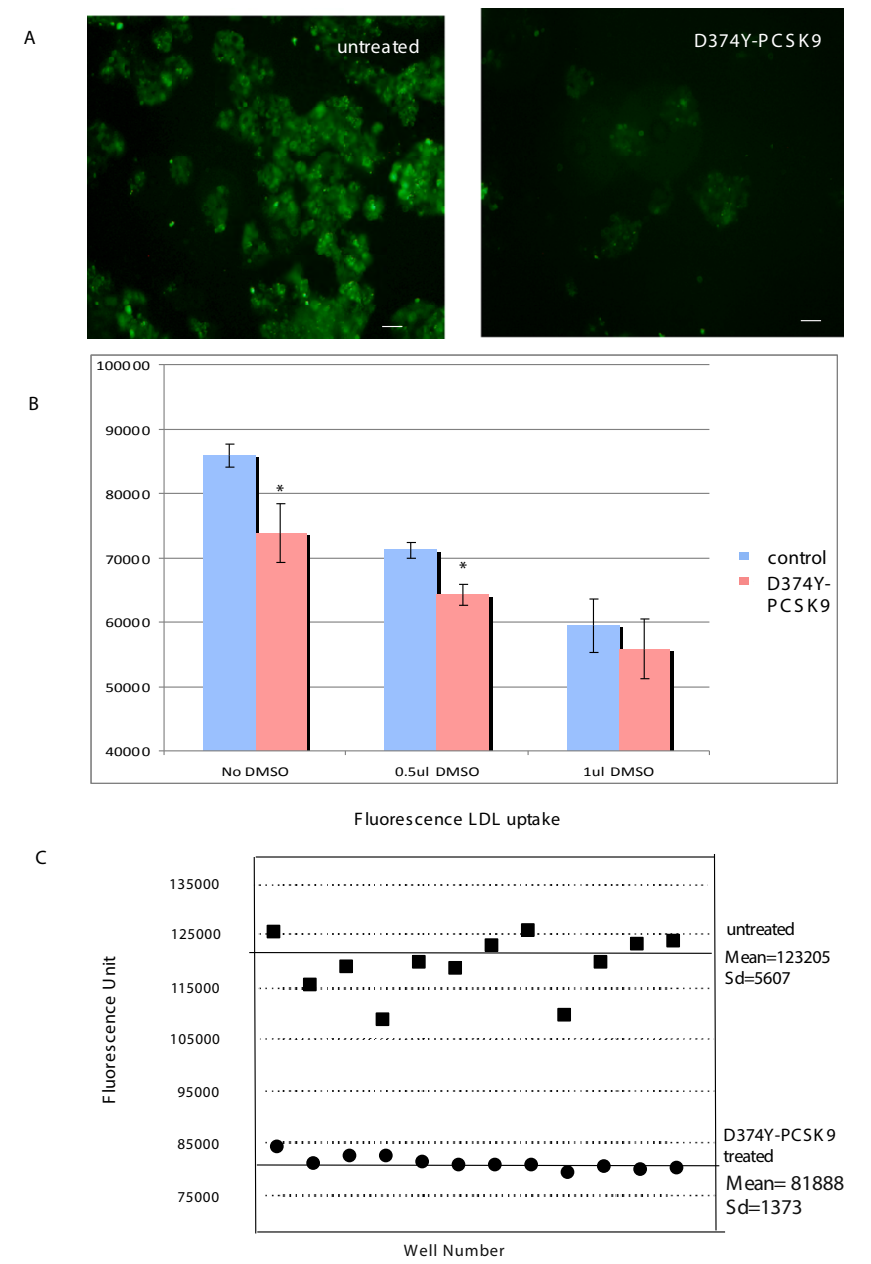

Figure 1: Cell-based PCSK9-mediated LDL uptake inhibition function assay with recomninant D374Y-PCSK9 protein. A. Fluorescence labelled LDL uptake in human hepatocellular HepG2 cells (control, left panel) and the HepG2 cells treated with $13.4 \mathrm{nM} \mathrm{D374Y-PCSK9}$ for $16 \mathrm{~h}$ (right panel). Bar, $20 \mu \mathrm{m}$. B. Effect of DMSO on the cell-based screening. HepG2 cells were incubated with the vehicle (PBS) and different dilutions of DMSO $(0.5 \mu \mathrm{l}$ or $1 \mu \mathrm{l}$ DMSO in $100 \mu \lambda$ medium) in D374Y-PCSK9 treated HepG2 cells. LDL uptake was quantified on the Fusion fluorescence plate reader. The average fluorescence reading $\pm S D$ are shown. ( ${ }^{*}<0.05$ vs. corresponding vesicle only, $n=3$ per group). C. Graphical comparison of the fluorescence readings from the samples of D374Y-PCSK9 treated and untreated. Each scatter plot represents relative fluorescence units (black round dot, D374Y-PCSK9 treated samples; black square, negative control) in different treatments. There was significant statistical significance (Student t-test, two tails, $P<0.05$ ) between the D374YPCSK9 treatment and control group. 
Citation: Xu W, Liu L (2013) An In vitro Cell-Based LDL Uptake Model for Screening PCSK9 Modulators. J Bioequiv Availab 5: 248-252. doi:10.4172/ jbb.1000168

\section{Screen the NINDS compound library}

Initially, a pool of 5 compounds was added into $100 \mu \mathrm{l}$ of medium in each well in 96-well plate format. In the positive control wells, PCSK9-D374Y protein (13.4 nM final concentration) was added. The negative control was culture medium with vehicle $(0.5 \% \mathrm{DMSO})$ only. After $16 \mathrm{~h}$, the medium was replaced with DMEM without serum. After $24 \mathrm{~h}$, the medium was replaced with fresh medium containing $10 \mu \mathrm{g} /$ $\mathrm{ml}$ Bodipy FL LDL without serum. The cells were incubated for $4 \mathrm{~h}$ at $37^{\circ} \mathrm{C}$. The cells were washed with PBS and LDL uptake was quantified on the Fusion fluorescence plate reader. We have successfully screening the NINDS compound library by pooling 5 compounds into each well (200 nM final conc.), screening by duplication (Figure 2). Hit molecule was defined as a molecule that gave significantly increased LDL fluorescence in the compound treated cells in comparison with untreated cells. Each screen was carried out in duplication. Only the hit polls on both duplicates were selected and broken down into each individual compound (Figure 2).

As shown on Figure 3, the wells that contain D374Y-PCSK9 protein had significant lower fluorescence-labeled LDL uptake in comparison with the control wells (untreated) (Figure 3, 1-2 column). Initially, we have identified 9 positive pools in total 209 pools, which contain all 1041 compounds. These 9 positive pools were then broken down to each individual compound and 6 positive hits have been detected in a duplication assay (Figure 3, column A-F, Table 1).

\section{Western blot analysis}

We next used the western blot assay to access the 6 potential hits identified by the HTS assay. HepG2 cells were treated with $1 \mu$ / $\mathrm{ml}$ PCSK9-D374Y protein $(13.4 \mathrm{nM})$ together with each of the 6 compounds with $200 \mathrm{nM}$ final concentration. After $16 \mathrm{~h}$ in serumfree DMEM medium incubation, the whole cell extracts were isolated and subjected to western blot analysis with the anti-human LDLR antibody. As shown on Figure 4A, there was a significant increase of

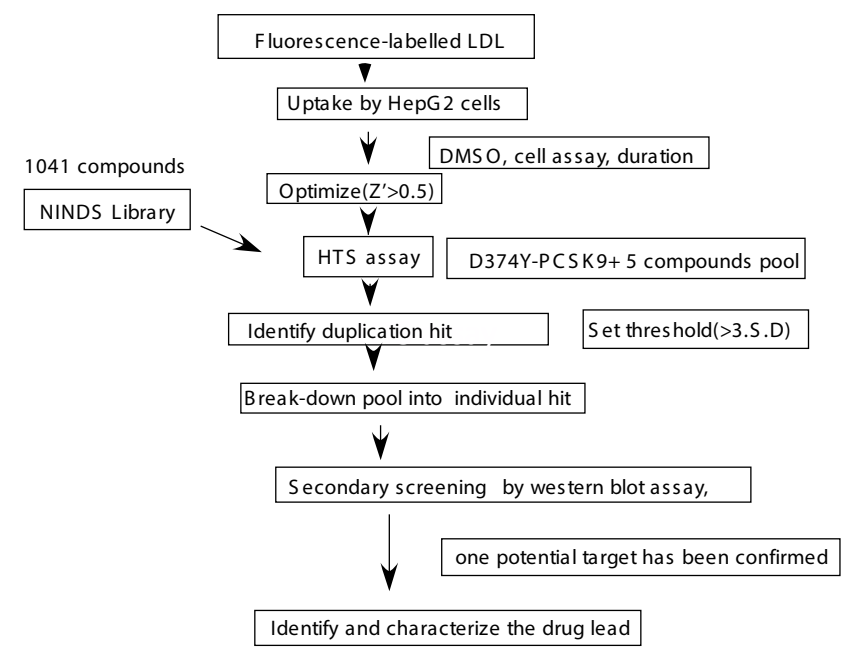

Figure 2: Experimental design of a cell-based high-throughput assay for identifying PCSk9 inhibitors. HepG2 cells were seeded in $2 \times 10^{5} / \mathrm{ml}$ in 96 -wells plate. Vehicle (PBS) or D374Y-PCSK9 protein (13.4 nM) was added in the culture medium with pooling 5 compounds into each well ( $200 \mathrm{nM}$ final conc.) from the NINDS library. The positive pools in duplication were broken down to each individual compound. Each individual positive compound was then subject to the secondary screen assay by western blot.

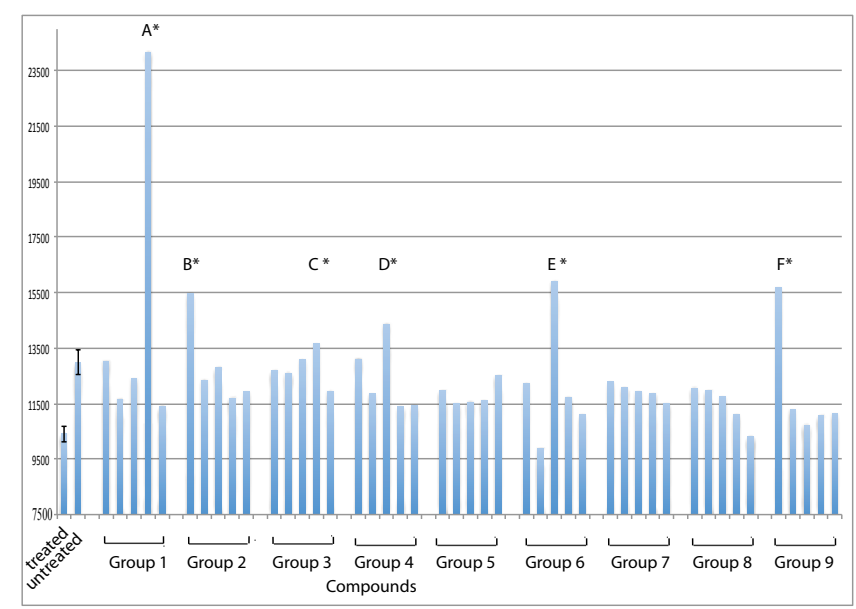

Figure 3: Representing readings of the fluorescence LDL uptake in the highthroughput assay. The positive pools (total 9) were broken down to each individual compound and 6 positive hits have been detected in a duplication assay to have significant higher LDL uptake than control wells ${ }^{*} p<0.05$ vs. corresponding vesicle only, $n=6$ ).

\begin{tabular}{|c|c|c|c|c|}
\hline Compounds & Molecule Name & fmla MolStructure & mol weight & therapeutic \\
\hline A & $\begin{array}{l}\text { Acriflavinium } \\
\text { Hydrochoride }\end{array}$ & C14H14CIN3 & 259.7408 & $\begin{array}{l}\text { antiinfective, } \\
\text { intercatalating } \\
\text { agent }\end{array}$ \\
\hline B & Chochicine & $\mathrm{C} 22 \mathrm{H} 25 \mathrm{NO} 6$ & 399.4477 & $\begin{array}{l}\text { antimitotic, } \\
\text { antigout } \\
\text { agent }\end{array}$ \\
\hline C & Sulpiride & $\mathrm{C} 15 \mathrm{H} 23 \mathrm{~N} 3 \mathrm{O} 4 \mathrm{~S}$ & 341.4323 & $\begin{array}{l}\text { dopamine } \\
\text { receptor } \\
\text { antagonist, } \\
\text { antipsychotic }\end{array}$ \\
\hline D & $\begin{array}{l}\text { Emodic } \\
\text { acid }\end{array}$ & $\mathrm{C} 15 \mathrm{H} 8 \mathrm{O} 7$ & 300.2268 & $\begin{array}{l}\text { cathartic, } \\
\text { purgative } \\
\text { agonist }\end{array}$ \\
\hline$E$ & Almotriptan & $\mathrm{C} 17 \mathrm{H} 25 \mathrm{~N} 302 \mathrm{~S}$ & 335.4717 & $\begin{array}{l}5 \mathrm{HT} \\
1 \mathrm{~B} / 2 \mathrm{D} \\
\text { receptor } \\
\text { agonist }\end{array}$ \\
\hline $\mathrm{F}$ & Creatinine & $\mathrm{C} 4 \mathrm{H} 7 \mathrm{~N} 3 \mathrm{O}$ & 113.1199 & $\begin{array}{l}\text { metabolic } \\
\text { enhancer }\end{array}$ \\
\hline
\end{tabular}

Table 1: List of the potential positive hits in the high-throughput assay.

LDLR protein in one of the compounds, compound B (colchicine) treatment (Figure 4A, lane 4). In fact, the level of LDLR in colchicine treated cells was similar to that of the untreated group (Figure 4A, lane 1). We further observed dose-dependent increase of the LDLR protein content (Figure 4B). The half maximum inhibition of colchicine to PCSK9-D374Y degradation of LDLR protein was calculated as 0.131 $\mu \mathrm{M}$ (Figure 4B)

Because colchicine is cytotoxic, we have examined the cell viability of HepG2 after colchicine treatment using the trypan blue exclusion method. We found that treatment of HepG2 cells at current low concentrations of colchicines $(0.05 \mu \mathrm{M}$ to $0.2 \mu \mathrm{M})$ had no observed toxicity in $16 \mathrm{~h}-24 \mathrm{~h}$ period (data not shown).

\section{Discussion}

Compound Colchicine discovered in our screen of PCSK9 inhibitor is a well known ancient remedy that has been used to treat gouty arthritis over 1,400 years (Alexander of Tralles during the $6^{\text {th }}$ century) [13]. More recently, FDA proved colchicine as a prescribing drug for 
A

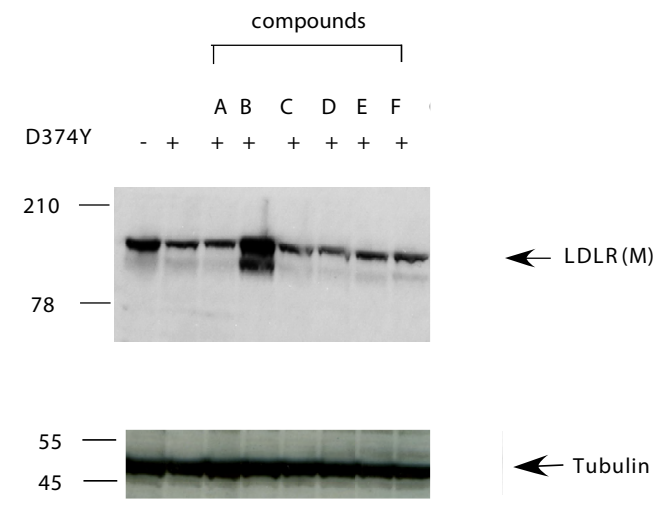

B

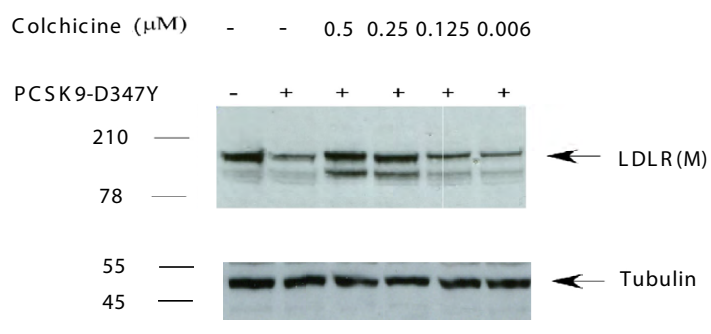

IC 50 of inhibition of PCSK 9-D374Y by colchicine

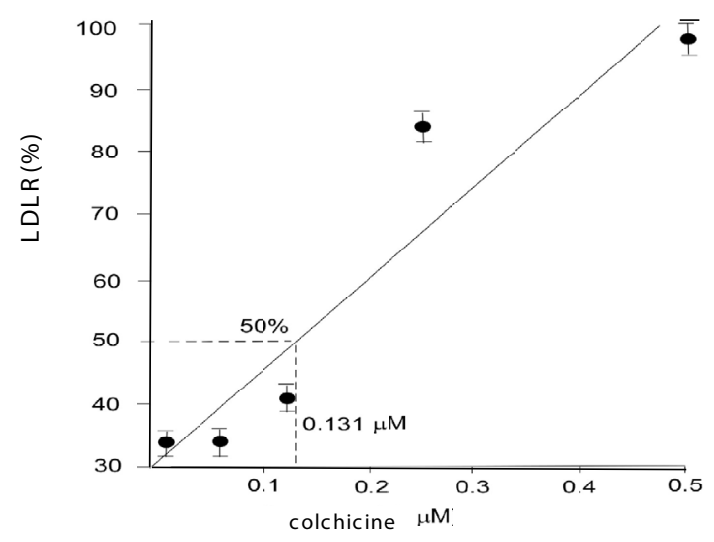

Figure 4: Screening analysis of PCSK9-mediated LDLR degradation by western blot. A. 6 positive compounds (compound A-F) were added to the culture medium individually with D374Y-PCSK9 to HepG2 cells. Reduction of endogenous mature LDLR (M) in HepG2 cells was analyzed by western blot. Compound B ( Figure 4, lane 4, Table 1, colchicine) has been detected to inhibit D374Y-mediated LDLR degradation, showing increased LDLR afte treatment. Equal loadings were confirmed using anti tubulin antibody. B. Dose response of the compound $B$ (colchicine) on inhibiting D374Y-mediated LDLR degradation in the western blot analysis. The ratio of LDLR/tubulin in untreated sample (Figure 4, lane 1) was assigned a value of $100 \%$. The ratio of LDLR/ tubulin in D374Y-PCSK9 treated sample $(13.4 \mathrm{nM}, 16 \mathrm{~h}$, Figure 4, lane 2) has a value of $25 \%$. Four different concentrations of colchicine were used to calculate the IC50 of inhibition of PCSK9-D374Y by colchicine $(n=3)$. The IC was $0.131 \mu \mathrm{M}$.

treatment of acute gout flares and familial Mediterranean fever [14]. Despite its historical role in gout, the metabolic effects of colchicine have not been explored. Therefore, our finding on colchicine inhibition of PCSK9 degradation of LDLR is a novel finding and giving an ancient remedy a new usage for cardiovascular disease treatment.
In fact, looking for past literatures we found there are two previous reports showing cholesterol lowing effects of colchicine. In 1967, Faloon et al reported that in six obese patients receiving constant lowcalories diet, being treated with colchicine, serum cholesterol fell by 40 to $80 \mathrm{mg} / 100 \mathrm{ml}$ in 6 days in four of the five patients [15]. Again, in the 1970, Rubulis et al reported the two hypercholesterol patients have been shown significant fall in serum cholesterol in 5 days treatment of colchicine $2.5 \mathrm{mg}$ daily [16]. Despite these reports, the metabolic effects of colchicine on cholesterol regulation have not been explored. Our high-throughput result has pointed for the first time that colchicine interaction with PCSK9LDLR pathway could be its key function in mediation of cholesterol regulation.

Colchicines is known as a potent binder to tubulin in the microtubules network [17]. Interestingly, a recent study has shown that the endocytic recycling of the LDL receptor returning to the plasma membrane depends on microtubule-dependent motility [18]. In a separate in vitro cell culture model of the Alzheimer's disease, increased APP expression and A $\beta$ exposure alters microtubule function, leading to reduced transport of LDLR to the plasma membrane, moving it toward the Golgi apparatus and lysosomes [19]. PCSK9 is known forming a complex with LDLR in the early endosomes and lysosomes [8], that makes the PCSK9/LDLR complex is likely moving on the microtubules network, which is vulnerable to the disruption by colchicine. The detail mechanism of colchicine/PCSK9 action remains to be further explored.

\section{Conclusion}

We set up a cell-based HTS screen assay for PCSK9 inhibitors and screened a NINDS compound library with 1041 compounds. We have identified a chemical hit-Colchicine in this assay and used western blot assay as a secondary assay to further confirm that colchicine inhibited PCSK9 mediated LDLR degradation, highlighting the potential of the novel use of this drug for cardiovascular disease treatment.

\section{Acknowledgements}

We thank Professor David Hornby for his helpful advice and discussions throughout the project. We gratefully acknowledge Karen Holland for performing high-throughput screening in the HTS facility in the University of Sheffield. We are also very grateful to Dr. Catherine Kettleborough and Dr. Nicole Mathon in MRC Technology, UK for kindly supplying us a NINDS library.

\section{References}

1. Abifadel M, Varret M, Rabes JP, Allard D, Ouguerram K, et al. (2003) Mutations in PCSK9 cause autosomal dominant hypercholesterolemia. Nat Genet 34: 154-156.

2. Ooi EM, Barrett PHR, Watts GF (2013) The extended abnormalities in lipoprotein metabolism in familial hypercholesterolemia: Developing a new framework for future therapies. Int J Cardiol 168: 1811-1818.

3. Seidah NG, Prat A (2007) The proprotein convertases are potential targets in the treatment of dyslipidemia. J Mol Med (Berl) 85: 685-696.

4. Cohen JC, Boerwinkle E, Mosley TH Jr, Hobbs HH (2006) Sequence variations in PCSK9, low LDL, and protection against coronary heart disease. $\mathrm{N}$ Engl J Med 354: 1264-1272.

5. Frank-Kamenetsky M, Grefhorst A, Anderson NN, Racie TS, Bramlage B, et al (2008) Therapeutic RNAi targeting PCSK9 acutely lowers plasma cholesterol in rodents and LDL cholesterol in nonhuman primates. Proc Natl Acad Sci U S A 105: 11915-11920.

6. King A (2013) Lipids. Antibodies against PCSK9--a new era of therapy. Nat Rev Cardiol 10: 1.

7. Xu W, Liu L, Charles IG, Moncada S (2004) Nitric oxide induces coupling of mitochondrial signalling with the endoplasmic reticulum stress response. Nat Cell Biol 6: 1129-1134. 
Citation: Xu W, Liu L (2013) An In vitro Cell-Based LDL Uptake Model for Screening PCSK9 Modulators. J Bioequiv Availab 5: 248-252. doi:10.4172/ jbb.1000168

8. Xu W, Liu L, Hornby D (2012) C-IAP1 binds and processes PCSK9 protein: linking the C-IAP1 in a TNF-Ît pathway to PCSK9-mediated LDLR degradation pathway. Molecules 17: 12086-12101.

9. Aiken CT, Tobin AJ, Schweitzer ES (2004) A cell-based screen for drugs to treat Huntington's disease. Neurobiol Dis 16: 546-555.

10. Wang W, Duan W, Igarashi S, Morita H, Nakamura M, et al. (2005) Compounds blocking mutant huntingtin toxicity identified using a Huntington's disease neuronal cell model. Neurobiol Dis 20: 500-508.

11. Wyllie DH, Sogaard KC, Holland K, Yaobo X, Bregu M, et al. (2012) Identification of 34 novel proinflammatory proteins in a genome-wide macrophage functional screen. PLoS One 7: e42388.

12. Zhang JH, Chung TD, Oldenburg KR (1999) A Simple Statistical Parameter for Use in Evaluation and Validation of High Throughput Screening Assays. J Biomol Screen 4: 67-73.

13. GRAHAM W, ROBERTS JB (1953) Intravenous colchicine in the management of gouty arthritis. Ann Rheum Dis 12: 16-19.
14. Cerquaglia C, Diaco M, Nucera G, La Regina M, Montalto M, et al. (2005) Pharmacological and clinical basis of treatment of Familial Mediterranean Fever (FMF) with colchicine or analogues: an update. Curr Drug Targets Inflamm Allergy 4: 117-124.

15. Faloon WW, Webb DI, Race TF (1967) Cholesterol lowering effect of colchicine. Ann Intern Med 66: 1058-1058.

16. Rubulis A, Rubert M, Faloon WW (1970) Cholesterol lowering, fecal bile acid and sterol changes during neomycin and colchicine. Am J Clin Nutr 23: 12511259.

17. Lu Y, Chen J, Xiao M, Li W, Miller DD (2012) An overview of tubulin inhibitors that interact with the colchicine binding site. Pharm Res 29: 2943-2971.

18. Lakadamyali M, Rust MJ, Zhuang X (2006) Ligands for clathrin-mediated endocytosis are differentially sorted into distinct populations of early endosomes. Cell 124: 997-1009.

19. Abisambra JF, Fiorelli T, Padmanabhan J, Neame P, Wefes I, et al. (2010) LDLR expression and localization are altered in mouse and human cell culture models of Alzheimer's disease. PLoS One 5: e8556. 